\title{
ANÁLISIS DEL DISCURSO EN LA ERA DIGITAL. UNA RECOPILACIÓN DE CASOS DE ESTUDIO - BOOK REVIEW
}

\author{
by Eroulla Demetriou \\ University of Jaén, Spain
}

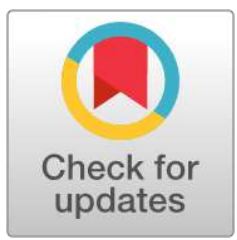

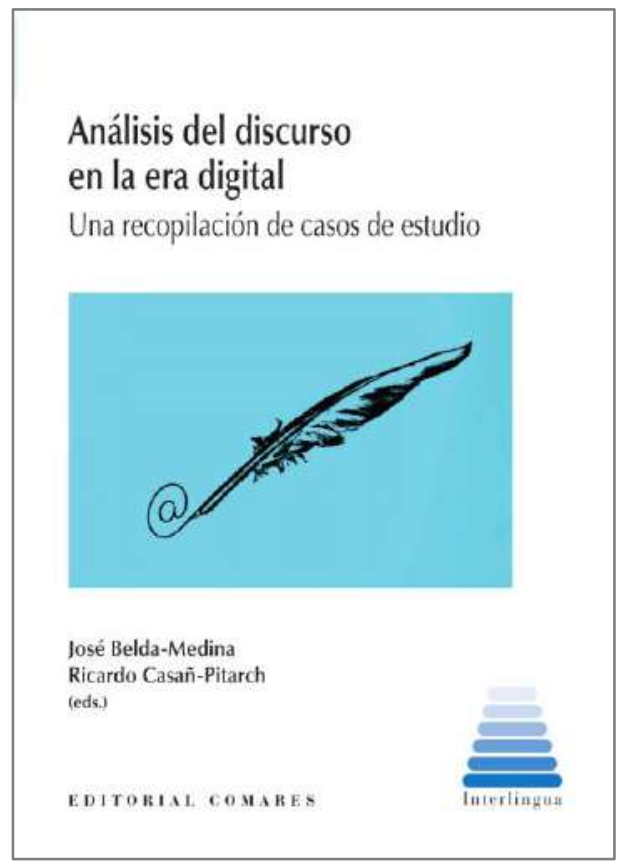

Copyright (C) 2021 Eroulla Demetriou

\section{Book details}

Title:

Análisis del discurso en la era digital. Una

recopilación de casos de estudio

\section{Editors:}

Belda-Medina, José and Casañ-Pitarch, Ricardo

Publisher:

Comares S.L., 152 pages

Year of publication:

2020

ISBN: 978-84-9045-999-76

https://orcid.org/0000-0003-1287-9457

This open access article is published and distributed under a CC BY-NC 4.0 International License which permits non-commercial use, distribution, and reproduction in any medium, provided the original author and source are credited. Permissions beyond the scope of this license may be available at eroulla@ujaen.es. If you want to use the work commercially, you must first get the authors' permission.

Citation: Demetriou, E. (2021). Análisis del discurso en la era digital. Una recopilación de casos de estudio - Book Review. English Studies at NBU, 7(1), 119-123. https://doi.org/10.33919/esnbu.21.1.8

Eroulla Demetriou is an Associate Professor at the University of Jaén where she has been working since 2007. Her research interests are mainly literature based, as she specialises in propagandistic Renaissance literature, the Black Legend of Spain, the Other in Modern English literature and Thomas More. She also enjoys research on Children's and Young Adults' literature.

E-mail: eroulla@ujaen.es 
Communication among human beings cannot be stopped. More specifically, digital communication is the sign of our times and the main symbol of developed western civilization in the late $20^{\text {th }}$ and early $21^{\text {st }}$ century. Even though the "digital era" was inexorably on the rise in recent decades even before the coronavirus raised its ugly head in 2020, now it is relentlessly bound to increase its presence and keep a firm grip on our daily routine. Digitalization has come to stay and the number of routes deriving from the new circumstances of imposed limitation of human contact, interaction and intercourse are expected to grow and grow: the sky is the limit. The research currently carried out worldwide on discourse analysis continues to be constantly updated and enriched. This has been more so in the last forty years thanks to the new-fangled approaches provided by the seminal contributions of Spitzer, Harris, van Dijk or Keller, to name but a few of the most relevant scholars. Evidence of this increasing trend of exploration within the boundless confines of the new technologies in linguistic communication is the latest book by editors José Belda-Medina and Ricardo Casañ-Pitarch.

Análisis del discurso en la era digital consists of a collection of eight samples of the research currently in progress in Spanish universities and in some other southern European universities. The volume first attracts the scholarly reader's eye due to the variety of different approaches employed by its authors. The eight chapters demonstrate the sheer abundance and diversity of paths that discourse analysis offers the digital era in which we are deeply immersed today and which we will presumably still be in the following decades to come. Each one of the eight chapters introduces a new way of showing the power of digitalization in Arts and Humanities.

Belda-Medina and Casañ-Pitarch's choice of contributions aims to pursue this fashion of exploration. Indeed, their book deploys the profound research duly carried out by a number of (mainly) Spanish authors and boasts a wide number of distinct approximations in the multidisciplinary field of digital discourse, a subject in constant growth. The book is "about" different digital perspectives used to address discourse analysis, as the editors clearly write in their "Introducción" (xi-xiii). It does not aim to scrutinize the different approaches of discourse analysis (nor does it offer an updated taxonomy) but to provide specific and realistic cases within the digital context, especially now, in the times of irritating curfews, lockdown and confinement due to the COVID-19 pandemic. 
Raúl Díaz Rosales, author of "Avances tecnológicos en lexicografía: las fronteras de una revolución (pendiente)" (pp. 1-13), focuses on the technological advances of lexicography and the clash of commercial interests existing between more conservative lexicographers who struggle to maintain paper dictionaries and more modern lexicographers who aim at digitalizing reference books for practical and economic reasons (low cost, constant updating, hyper-textuality, compatibility, multimedia, personalization, easy portability, reduced space, democratization of knowledge, etc.). Díaz Rosales pays special attention to electronic formats and digital editions of Diccionario de la Real Academia de la Lengua Española, Diccionario Clave, María Moliner's Diccionario de uso del español, RAE’s Nuevo Diccionario Histórico, etc.

Rocío Díaz-Bravo and Gael Vaamonde have authored "Creación de ediciones digitales para lingüistas de corpus: el caso del Retrato de la Loçana andaluza" (pp. 15-36), where they have diligently shown the simultaneous philological and linguistic possibilities of the digital edition of the Renaissance priest Francisco Delicado's dialogued novel. Indeed, Lozana Digital constitutes an example of an analysis of a literary text (which is characterised for its abundance in oral and colloquial expressions) through the creation of a normalized, lemmatised and annotated corpus. In this specific case, the authors have combined discourse analysis methodology with corpus linguistics and the employment of the online platform TEITOK.

Juan Rojas García uses his chapter "Application of topic modelling for the extraction of terms related to named bays" (pp. 37-55) to explain how to obtain geographical terminology about worldwide bays from coastal engineering texts, for which he employs LexiCon, a terminological resource specially created by the University of Granada. His purpose is to aid the user/translator to have access to different types of relevant knowledge on vocabulary and terminology about this specific domain of environmental science (such as their categorization, the relationship existing between different levels and the semantic roles of these geographical terms, etc.).

In "Primeras catas en un corpus de textos museísticos traducidos (inglésespañol)" (pp. 57-73), Jorge Leiva Rojo has concentrated on the analysis of twenty-one museum and art gallery webpages of New York City originally written in English and later translated into Spanish in the last twenty years and collected and grouped into two different sub-corpora, musa19en and musa19es. Special attention has been granted to the 
use of the word "curator", usually translated as "comisario" or "conservador" in Peninsular Spanish and "curador" in overseas Spanish. The author also shows his surprise at discovering that the key terms most amply used in these texts are related to cognitive deficiencies such as "Alzheimer" and "dementia" and their Spanish equivalents.

In Elena Domínguez Romero’s chapter “Digital newspaper readers’ use of visual evidential positioning strategies towards immigration" (pp. 75-85), the author constructs a corpus based on the reactions of Spanish online newspaper readers to the current Spanish Prime Minister's immigration policies. Her intention is to study the readers' use of visual, conceptual and social communication-based evidential positioning strategies which, she concludes, are based on distribution and usage and are conditioned by the presumed ideologies of the readership of each of the selected Spanish newspapers. She pays special attention to the use of the verb "ver" and subsequent visual-based constructions in the digital press.

In "Stative and dynamic perception verbs at the syntax-semantics interface" (pp. 87-101), Rocío Puerto-Cano uses SynSem Interface and the Sketch Engine corpus tool to elucidate the connection existing between syntax and semantics by analysing the relationship between stative and dynamic verbs of perception found in several relevant monolingual dictionaries and the databank The British National Corpus. She reaches the conclusion that it is more relevant to speak of different stative and dynamic meanings than of stative and dynamic verbs. She attributes this change of meaning in stative and dynamic verbs to the role of metaphorical language ("metaphorical extension").

Amal Haddad-Haddad uses her chapter "Climate change neologisms: a case of direct translation in an English-Arabic corpus" (pp. 101-116) to concentrate on the generation of scientific neologisms in Arabic, a specially challenging process taking in to consideration that English and Arabic are culturally very distant languages. HaddadHaddad emphasizes the need to use sets of metaphorical linguistic expressions to be able to realise the appropriate translation processes. She therefore analyses the metaphorization process in the domain of climate change, more specifically in the "coral bleaching" metaphor in both languages. In order to do so she applies the principles of the cognitive approach known as Frame-Based Terminology.

Finally, Raluca Levonian, author of "Virtual war and real peace: the presentation of the North-Atlantic alliance in social media discourse" (pp.117-135), studies the corpus 
of messages that has been published in the last two or three years in Facebook by the NATO Force Integration Unit of Romania in relation to issues related to peace and war. A pragmalinguistic perspective has been employed by Levonian to show the relevance of Facebook messages and other social media discourse to create a positive atmosphere and disposition in the shaping of public opinion and the popularization of specialised knowledge.

Another aspect of the book is the two languages employed. Out of eight chapters, three (as well as the Introduction) are written in the Spanish language and five in English. This is undoubtedly a clear sign of the intention of universality that the editors wish to grant to the scope of their book. Although the different chapters have been predominantly written in Spanish and English, other languages are also analysed on its pages: examples are provided in Arabic, Italian and Romanian too. From a more formal stand, even though the written idiolects of the nine contributions do naturally vary from one author to the other, the editors have made sure that they all have in common an admirable academic decorum and clarity of speech that denote an efficient editing technique. However, as any human work rarely reaches perfection, some minor slips of the pen have been found, the most serious of which appear in the titles in two of the English contributions: "an englisharabic corpus" (ch. 7) or "north-atlantic alliance" (ch. 8), or even in the use of the odd colloquial expression such as "pretty similar" (p. 100) in the main text.

Belda-Medina and Casañ-Pitarch's Análisis del discurso en la era digital constitutes a multifarious mosaic of digital approaches used to spread knowledge. The joint effort made both by editors and contributors is an attempt to construct an innovative (and certainly colourful) palette in the ever-changing world of linguistic research. The book fulfills its two main objectives, that is, to allow the avid researcher to get to know and understand the digital revolution from a practical linguistic perspective and to encourage future scholars to search for new paths towards a more interlinked world to disseminate culture, knowledge and wisdom. Indeed, this work certainly constitutes a fine example of an updated snapshot of the current state of digital linguistics and should therefore not be absent from scholarly library shelves.

\section{References}

Belda-Medina, José \& Casañ-Pitarch, Ricardo. (Eds). (2020). Análisis del discurso en la era digital. Una recopilación de casos de estudio. Comares S.L. 